\title{
Arriscar a vida por uma corrida: risco e corridas ilegais de carros e motos
}

Jeolás LS. Risking your life for a race: risk and illegal automobile and motorcycle street races. Interface (Botucatu). 2018; 22(67):1173-82.

The objective of the present article is to analyze the practices and meanings produced by youths involved in illegal automobile and motorcycle street races and radical maneuvers. This ethnographic study sought to understand risk behaviors among racers and the meaning they attribute to danger, adventure and the body sensations experienced in their practices. To this end, the authors had to adopt a broader meaning of risk and understand certain practices as a counterpoint to biopolitics or forms of life control. The racers are young individuals from lower-income classes, who respond to social impotence, which deprives them of economic (and social) capital, by using technological capital. This gives them status among their peers and social visibility, even if in contraband, as these practices are illegal, and their risks and adventures become a constituting element of identity construction.

Keywords: Youth. Risk behaviors. Automobiles and motorcycles. Illegal street races
O artigo propõe analisar práticas e produção de significados de jovens aficionados por corridas ilegais de carros e de motos ("rachas") e por manobras radicais. A pesquisa etnográfica busca compreender as condutas de risco entre os "rachadores" e o sentido que eles próprios atribuem ao perigo, à aventura e às sensações corpóreas presentes em suas práticas. Isso obriga a alargar os significados de risco e compreender determinadas práticas como contraponto às biopolíticas ou às formas de controle da vida. Os "rachadores" são jovens de classes populares e respondem à impotência social, que os destitui de capital econômico (e social), mediante um capital tecnológico que lhes permite reconhecimento de seus pares e visibilidade social, mesmo que a contrabando, em razão da ilegalidade dessas práticas, quando o risco-aventura torna-se um constitutivo da construção identitária.

Palavras-chave: Juventude. Condutas de risco. Automóveis e motocicletas. Corridas ilegais. (a) Departamento de Ciências Sociais- $\mathrm{CLCH}$, Universidade Estadual de Londrina. Rodovia Celso Garcia Cid, PR 445, km 380, Campus Universitário. Londrina, PR, Brasil. 86057-970. leilajeolas@gmail.com 


\section{Introdução}

Este artigo traz questões oriundas de pesquisa etnográfica sobre práticas e produção de significados de jovens aficionados por corridas ilegais de carros e motos ("rachas") e por manobras radicais. Para tanto, abordarei o lugar do risco e da aventura nessa manifestação das chamadas "culturas juvenis", através dos sentidos que os próprios "rachadores" atribuem às suas práticas, o que me obrigou a alargar os significados de risco como contraponto à biopolítica, ou seja, da apreensão da vida pela política.

A pesquisa aborda jovens que se lançam em corridas ilegais e em manobras radicais de forma a buscarem a experiência com o risco; jovens que provocam desafios e arriscam a vida, de maneira mais deliberada, se assim se pode afirmar, contrariamente aos discursos formais e institucionais, nos quais os riscos são negados e controlados na atual sociedade tecnologizada e securitária.

Os dados sobre mortes em acidentes de trânsito, como um dos problemas que mais afeta os jovens brasileiros, instigaram a pesquisa. Apesar dessa evidência, tal tema é pouco estudado nas Ciências Sociais, sendo pesquisado na Saúde Coletiva com prioridade para a epidemiologia dos acidentes de trânsito, uma vez que as estatísticas colocam o país em evidência neste campo. O automóvel se tornou um fenômeno de massa e, com isso, o aumento de acidentes e mortes transformou-se em fenômeno social a ser analisado, como indicado por Marin e Queiroz'. Jovens do sexo masculino são as principais vítimas de acidentes no país, de acordo com estudo sobre mortes por causas externas de Souza e Minayo $^{2}$. Dados de pesquisa realizada em Londrina/PR apontam que acidentes de trânsito e traumas decorrentes apresentam-se como um problema de saúde pública. A pesquisa realizada por Bastos, Andrade e Soares ${ }^{3}$ no Serviço Integrado de Atendimento ao Trauma e às Emergências, de 1997 a 2000 , demonstra que, das 14.474 vítimas registradas, mais de $70 \%$ era do sexo masculino e tinha de 10 a 39 anos; além disso, os motociclistas foram o principal tipo de vítima em todos os anos, com valores superiores a $40 \%$. Entretanto, não se pode determinar a percentagem dos acidentes causados pelas corridas clandestinas (os "rachas") com relação ao cômputo geral dos acidentes, em razão da carência de dados. A radicalidade dessas práticas merece atenção, uma vez que recentemente adquiriram visibilidade na mídia, apesar de existirem no Brasil desde os anos 1960, de acordo com Carmo ${ }^{4}$.

$\mathrm{Na}$ literatura internacional, Featherstone ${ }^{5}$ chama atenção para o fato de que o interesse voltado para o estudo do movimento e da mobilidade na vida social não foi acompanhado de estudos sobre o automóvel. Embora a velocidade tenha adquirido valor central nas sociedades ocidentais, como bem aponta Cunha ${ }^{6}$ e outros autores como Sennett 7 , que a ressaltaram como um dos traços da revolução urbano-moderna, o trânsito e o automóvel ainda merecem estudos mais aprofundados nas Ciências Sociais.

No Brasil, o antropólogo Roberto da Matta e dois pesquisadores - Vasconcellos e Pandolfi ${ }^{8}$ examinaram a cultura do trânsito capixaba e ressaltaram hábitos, posturas e valores de motoristas e usuários. Eles analisaram atitudes ligadas à agressividade, à imprudência e à confiança na impunidade, ilustrando a hipótese da coexistência de valores igualitários e hierárquicos na sociedade brasileira. De acordo com os autores, faz-se necessário compreender os comportamentos agressivos e egoístas no trânsito para se alcançar o entendimento dos altos índices de mortes no país.

No caso do estudo dos "rachas", foram dois os pressupostos que orientaram a pesquisa e que apontaram, justamente, para a ambivalência da relação existente com o risco presente nessas práticas: de um lado, a íntima relação que os "rachadores" desenvolvem com motores e velocidade ao longo do processo de socialização minimiza os riscos vivenciados; e de outro, a existência de valores próprios de uma forma tradicional de masculinidade hegemônica, exibidos por meio da confirmação pública de coragem e audácia, potencializa o risco aí presente.

\section{Metodologia: pesquisa de campo "em movimento"}

Trata-se de um trabalho de campo, realizado ao longo de cinco anos (2007-2012) e que acompanhou "rachadores", interlocutores da pesquisa, em ruas e estradas da cidade de Londrina/ 
$\mathrm{PR}$, bem como no autódromo local, em uma tentativa de enquadramento e institucionalização dessas práticas perigosas.

O método etnográfico permitiu o cotejamento da observação das práticas sociais e da fundamentação teórica. Os dois fundamentos principais do método continuam pertinentes: os comportamentos humanos só podem ser apreendidos se levados em conta os contextos sociais nos quais atuam e a necessidade de se apreender o ponto de vista do outro. Entretanto, a mediação necessária entre conceitos teóricos e nativos, ou entre teoria e observação empírica, continua a ser o desafio maior da etnografia, de acordo com antropólogos de referência nacional como Peirano9 Woortman ${ }^{10}$ e Goldman ${ }^{11}$. Trata-se de realizar o diálogo entre o dado observado e sua interpretação, orientada pela teoria, tentando superar as descrições meramente fenomenológicas.

O método etnográfico vem sendo repensado contínua e criticamente, pois se, inicialmente, aplicava-se a estudar sociedades tradicionais, indígenas ou "tribais" em suas dimensões de totalidade, ao se voltar para o estudo das sociedades moderno-contemporâneas, teve que ser readequado em suas técnicas e abordagens, adaptando-se aos novos campos de pesquisa e objetos de estudo mais complexos, não apenas focados em um grupo circunscrito no espaço e no tempo. De acordo com Marcus $^{12}$, o mundo globalizado e as sociedades transnacionais exigem etnografias multissituadas. No caso das pesquisas etnológicas realizadas entre populações indígenas brasileiras que apresentam ritmos descontínuos, visitas mais ou menos curtas ao longo de um amplo período de campo foram denominadas por Ramos ${ }^{13}$ de "etnografias em movimento".

No caso dos "rachas", prática ilegal que ocorre sem lugar ou hora marcada, foi necessário enfrentar esse desafio, desenvolvendo uma pesquisa-percurso ${ }^{14}$. Inicialmente, analisei conteúdos de listas de discussão na internet tendo os "rachas" como foco de interesse. Esse procedimento ajudou-me a conhecer a linguagem e os significados desse universo fundamentalmente masculino, na sociedade brasileira, e diante do qual me sentia como "estrangeira". Em seguida, com ajuda de um estudante e "rachador", que serviu de guia e assistente de pesquisa, pude me familiarizar e participar das atividades de grupos atuantes na cidade.

Dessa forma, a pesquisa etnográfica utilizou várias técnicas e abordagens: pesquisa na internet; pesquisa de campo em quatro locais da cidade (duas vias de circulação rápida; uma praça e posto de gasolina; e o autódromo), com observação e elaboração de caderno de campo; conversas informais e entrevistas formais registradas e transcritas; e registro de fotos e vídeos ${ }^{15,16}$. A pesquisa de campo foi aprovada pelo Comitê de Ética em Pesquisa da UEL, garantindo que os procedimentos seguidos estivessem de acordo com o respeito ao anonimato dos participantes.

O perfil dos "rachadores" mostrou-se heterogêneo, a não ser pelo fato de serem todos do sexo masculino. A faixa etária de 18 a 40 anos aponta uma dificuldade em qualificá-los de jovens, apesar de todos desenvolverem desde cedo, na infância ou pré-adolescência, o gosto pelos motores. Suas referências são pais, tios, irmãos mais velhos, primos ou amigos e começam as práticas com carros e motos como lazer ou como trabalho informal e precário. Alguns já formaram família, outros moram ainda com os pais. A juventude parece, então, referir-se mais ao sentimento de "ser jovem" ligado a essas práticas do que aos limites fixados pela idade.

\section{Busca da adrenalina: riscos sofridos/negados versus riscos corridos/buscados}

Dos riscos que "sofrem" para os riscos que "correm" ou "buscam", há um "deslocamento" de sentido que enfatiza a ação ativa desses atores. É verdade que essa tal distinção é imprecisa, uma vez que dicotomiza e simplifica uma relação mais complexa, mas ressalta diferenças existentes nas tradições discursivas relacionadas à gestão da vida, por meio da comunicação sobre risco, como nos ressalta Menegon e Spink ${ }^{17}$ : risco-perigo, próprio do senso comum e referente aos infortúnios que fogem às possibilidades de cálculo e previsão; risco-probabilidade, que remete a discursos e sentidos sobre riscos como estratégias de governamentalidade; e risco-aventura, que herda o sentido de positividade da aventura. Tais tradições discursivas e seus conteúdos coexistem e dão indicações sobre o desenvolvimento histórico da noção de risco. 
Os sentidos de risco-aventura apontam para a necessidade de se reconhecer que as teorizações sobre risco precisam incorporar também o sentido de risco buscado, almejado, enfrentado. São os perigos corridos mais "deliberadamente" e valorizados por parte de grupos e redes de jovens de diferentes classes sociais. Eles se afirmam como sujeitos-atores que fazem apreciações positivas de suas performances. Tal abordagem implica compreender como os atores sociais vivem e representam os riscos presentes em suas práticas e experiências. Pesquisadores com Mary Douglas ${ }^{18,19}$ e Peretti-Wate $^{20}$ enfatizam o plano da percepção dos riscos e suas implicações culturais e sociais. Nessa perspectiva, Le Breton ${ }^{21,22}$ ressalta o gosto pelo risco por parte daqueles que não o evitam, mas buscam e valorizam sua experiência, tais como empreendedores, desportistas, guerreiros, entre outros. Esses estudos possibilitam aprofundar a compreensão da exposição dos sujeitos sociais às diversas formas de risco e à possibilidade - maior ou menor - de perder a vida, no contexto de uma sociedade obcecada por segurança, preservação e prolongamento da vida, como afirma Ribeiro23. Há ambivalência e ambiguidade entre a libertação da paixão e a gestão do risco; entre a busca de liberdade, ligada à transgressão das normas sociais, e a busca de segurança e proteção.

Um dos pressupostos da pesquisa é o de que, em suas performances, os jovens de classes populares (motos de baixa cilindrada) e os de camadas mais baixas da classe média (carros "tunados") respondem à impotência que os destitui de um capital econômico e social por meio de um capital tecnológico que lhes permite ganhar reconhecimento: eles "bricolam"/constroem não só suas máquinas, mas também uma imagem de si próprios, a fim de exibir potência e ganhar prestígio entre os seus pares. $O$ risco-aventura, portanto, necessita ser analisado como constitutivo das construções identitárias desses jovens, parte de suas políticas de existência, como espero aprofundar.

A primeira dificuldade enfrentada, logo de início, nas conversas espontâneas com os "rachadores", foi que eles não falam de risco, havendo uma ausência da ideia de risco-probabilidade, no sentido mais corrente da possibilidade de um evento negativo ocorrer. A dimensão do prazer, associado à velocidade, foi ressaltada em depoimentos, gestos e expressões de seus rostos, ao mesmo tempo em que há uma (quase) ausência do risco em seus discursos, contrapostas à ênfase do domínio técnico das máquinas e de suas performances como condutores.

Ressalto como tais práticas estabelecem uma contraposição à noção de risco como força negativa que ameaça a saúde e as políticas de prevenção. Elas se contrapõem à biopolítica, entendida como "apreensão da vida pela política", de acordo com os estudos de Foucault ${ }^{24,25}$ e ressaltado por Farhi Neto ${ }^{26}$, permitindo trazer para o debate a compreensão dessas práticas como resistência à forma como o Estado busca se encarregar de nossas vidas. Se as manifestações juvenis não têm o caráter de resistência de classe ou de transgressão contra instituições delimitadas, como a família ou a escola, e se aparecem como fragmentadas, elas podem ser compreendidas, no entanto, como formas de confrontação e de experimentações alternativas; um tipo de transgressão não mais de confrontação ao instituído que se almeja transformar, mas no sentido de uma rebelião latente contra uma sociedade vigiada e com tendência a amortecer corpos e consciências. Como afirma Ferreira ${ }^{27}$, elas não objetivam suprimir o sistema de dominação, mas "fissurá-lo micropoliticamente" (p. 114) e proporcionam, dessa forma, ganhos de singularização, autenticidade e reconhecimento sociais, mesmo em se tratando de práticas ilegais. As práticas dos "rachadores", que intensificam o presente e não se preocupam com o futuro, suscitam reprovação moral e são alvo de estereótipos e discriminação no contexto contemporâneo, em que prever o futuro tornou-se uma tendência, de acordo com Beck, Giddens e Lash $^{28}$.

\section{Os "rachas" entre o jogo e o rito, entre o prazer da velocidade e o desafio da coragem}

O cotejamento dos dados e da teoria permitiu uma análise que busca compreender o risco presente nos "rachas" como jogo e rito, ao mesmo tempo. Por meio da mediação entre as categorias nativas dos próprios sujeitos que definiram suas práticas e representações como "brincadeira", "diversão", "curtição" e as categorias analíticas de jogo e rito, cheguei à compreensão dos "rachas" como jogobrincadeira e rito de masculinidade. 
Os contornos entre jogo e rito são fluidos, pois diferentes tipos de jogos - de esportes a jogos eletrônicos - estabelecem limites porosos com os ritos, as cerimônias, a festa e o espetáculo, conforme apontam as discussões apresentadas por St-Germain e Ménard ${ }^{29}$ e Segalen ${ }^{30}$.

O que designei de jogo-brincadeira advém da categoria nativa "brincadeira", utilizada com recorrência pelos "rachadores" para se referirem às suas práticas de arrancadas, competições e manobras: o burnout ou borrachão (manobra de queimar pneus com o carro parado até estourarem); o "zerinho", "cavalo de pau" (manobra de fazer círculos com o carro acelerando e freando ao mesmo tempo); a "cadeira elétrica" (manobras radicais com carros preparados); o wheeling ("empinar" motos). O termo jogo-brincadeira expressa as dimensões de jogo e prazer que começam nos jogos de criança e passam pelas experiências lúdicas dos jovens, chegando às tentativas de controle da vertigem.

Por outro lado, a compreensão dos "rachas", não apenas como jogo-brincadeira, mas igualmente como ritos permanentes de virilidade, nas palavras de Le Breton ${ }^{31}$, permite focar a dimensão da competição, do desafio e da coragem expressos publicamente e de forma recorrente.

A pesquisa de campo mostrou que rito (definido no sentido estrito de ordem, regulação e hierarquização) e jogo (associado idealmente à liberdade, à espontaneidade e ao prazer) não são, na complexidade da realidade vivida, tão estritamente opostos e desconectados como aparecem em alguns modelos teóricos. Entre jogo e rito, as práticas e narrativas dos "rachadores" não podem ser compreendidas por meio de polarizações do tipo espontâneo/regrado, lúdico/sério, gratuito/competitivo, mas sim por inter-relações das dimensões citadas: jogo-brincadeira e rito de masculinidade.

\section{Jogo-brincadeira e "coisa séria": sensações corpóreas, emoções e intensificação da vida}

O corpo (e as sensações) nessas práticas retoma o seu uso como "instrumento sensorial", afirma Segalen ${ }^{30}$, e coloca em evidência a busca pela intensificação da vida e a fuga da rotina e da monotonia cotidianas. A automobilização acelerada desses jovens se dá por meio dos jogos e das brincadeiras que permitem a ruptura com os ritos do cotidiano e com a pressão das responsabilidades, utilizando, para tal, um domínio de liberdade e de possibilidades criativas. Portanto, o risco aí presente, ao invés de uma ameaça que deve ser eliminada é, ao contrário, um desafio constitutivo de uma vida intensa. $O$ sentido de suas práticas se distancia do sentido prevalente de risco como "efeito negativo" ou "dano", individuais ou coletivos, na linguagem de "grupos" e "fatores de risco"; e marca uma contraposição à abordagem dos riscos como efeitos colaterais ou produto das novas tecnologias.

Para a maioria desses jovens, "chamar para o racha" é uma diversão, ou seja, uma atividade voluntária e na qual o prazer e o lúdico ocupam o lugar central: "a gente pode fazer isso 24 horas por dia, sem parar, só curtindo"; "toda preocupação desaparece, você não pensa em nada". Desde crianças eles exercem com repetição o aprendizado dos motores. O prazer advém da fusão da potência corporal com a potência mecânica de suas máquinas, de uma sintonia entre corpo-máquina e suas primeiras experiências são vividas menos como risco e mais como brincadeira.

Esse é o sentido central do risco para os "rachadores": a busca da vertigem ou da (re)intensificação das sensações corporais, conforme Sennett ${ }^{7}$. O que importa para eles não é evidentemente evitar o risco, mas buscar experiências extremas nas quais a importância das sensações corporais se faz fundamental: a auditiva (som dos motores); a visual (faróis dos carros e motos que chamam para os "rachas"); a olfativa (cheiro do combustível e dos pneus); e a tátil (trepidação corporal): "Sensação de adrenalina no sangue, prazer, excitação, falta o ar, a gente fica fascinado"; "primeira vez que fiz um burnout eu não dormi durante uma semana"; "é tão bom como sexo, é melhor que trepar"; "cê fica com o pau duro, a gente fica rindo sozinho de prazer". São sensações que mudam os registros da percepção do tempo e do espaço (realidade suspensa), do peso e da gravidade do corpo.

Mas a vertigem para eles se produz em uma relação tênue entre falta de controle e controle, ou seja, brincadeira e diversão têm também um lado sério: "tem a ver com controle, domínio, concentração total, sensibilidade total, é adrenalina e o cara fica atento a tudo"; "Eu me deixo levar 
pela velocidade, por alguns segundos saio de mim, mas a atenção está sempre lá, como um pano de fundo". A vertigem é buscada sob o modo da aceleração e da derrapagem controladas, pois a "renúncia da consciência" e a "embriaguez dos sentidos", nas palavras de Le Breton", são breves e devem estar sob controle: "é adrenalina pura, mas o cara atento a tudo não só com o carro, mas com seu desempenho, com o cara do lado".

$\mathrm{Na}$ verdade, a relação dos "rachadores" com as máquinas é ambígua: colocando-se sensorialmente em sintonia com elas, buscam seu controle no limite da potência de cada uma, mas às vezes elas parecem tomar vida própria como se fosse "vício", "doença" ou "droga" - "pra quem gosta disso, é uma doença"; "nossa droga é nosso carro"; "tá no sangue"; "é um vício". Parece uma força contra a qual o sujeito pode muito pouco: "tava voltando pra casa, ouvindo um sonzinho, quando um carro me chamou pro racha". Nesse caso, o domínio (vertigem sob controle) é posto em xeque e, como na dependência e na doença, coloca em risco a própria vida.

Isso é reforçado pelo sentido de competitividade e pela vontade de ganhar, sempre presentes. Perder e ganhar são a essência dessas práticas: o melhor/mais rápido motor; a máquina melhor preparada; o melhor desempenho do piloto. A brincadeira faz interface com a competição, como no caso dos "rachadores" de moto que entram no vácuo da moto da frente para alcançar velocidade e tocar o pé do condutor (que corre deitado sobre a moto) para desequilibrá-lo e, dessa forma, ultrapassá-lo.

Essa relação entre controle e descontrole diz respeito aos locais da cidade onde ocorrem os "rachas", pois, em parte, são realizados nas ruas e estradas e, em outra parte, ocorrem quinzenalmente no autódromo local nas "sextas-quentes", levando em conta os dispositivos do Estado, da polícia e de saúde e transformando-se em metáfora das biopolíticas que buscam enquadrar e "civilizar" as condutas perigosas. Porém, a maior parte deles não se deixa "recuperar" pelas instituições que eles consideram disciplinares e "coisa de criança", pois a pista liberada é uma reta muito curta para alcançar velocidade, no caso das motos de baixa cilindrada, e o local vigiado com ambulância, bombeiros e seguranças representa apenas uma das possibilidades para a prática, sobretudo quando se trata da exposição dos carros e das performances e enquanto local de lazer. Esse circuito não permite, entretanto, os imponderáveis das ruas: "na rua tem mais emoção, mais adrenalina", "na rua tem o desafio de fazer uma curva mais rápido que o adversário". Poderíamos pensar na diferença proposta por Dunning e Elias ${ }^{32}$ entre "excitação séria", produzida pelas situações vividas no cotidiano em contato com perigos reais (a rua), e "excitação mimética", na qual a emoção é produzida pela mimese das situações reais no seio de espaços controlados (autódromo). Entretanto, a diferença entre rua e autódromo não é tão simples e nem de oposição, pois muitos dos jovens frequentam os dois locais e alguns enfatizam a possibilidade de "serem vistos" no autódromo, de "exporem" suas máquinas e suas performances. Os eventos no autódromo têm semelhanças com exposições, espetáculos, festas e encontros dos quais fazem parte comércio e mercado. O autódromo representa, dessa forma, uma metáfora dos dispositivos securitários e a rua, uma metáfora dos riscos corridos que transgridem os dispositivos biopolíticos.

\section{Rito de masculinidade e busca de reconhecimento}

Pensar a importância que o aspecto ritual ganha nos "rachas" pode ser explicado face às dificuldades de construção de identidades estáveis na atualidade, sobretudo quando os percursos de vida são fluidos, flexíveis e incertos e as transições não mais demarcadas por ritos comuns. As passagens são múltiplas, os percursos indeterminados e os ritos "bricolados" pelos sujeitos, uma vez que dificilmente podem contar com ritos unívocos que propiciam significações coletivas. Os ritos atuais marcariam as passagens de maneira mais individual do que coletiva, de forma mais privada do que pública, possibilitando reforçar a construção de uma identidade original e individual, mas não um sentido de pertencimento coletivo ou de mudança de status social, conforme apontam diferentes autores como Balandier ${ }^{33}$, Jeffrey, Le Breton e Levy ${ }^{34}$, Le Breton ${ }^{31}$ e Segalen ${ }^{30}$. 
Nesse sentido, as práticas de risco juvenis podem adquirir uma forma de passagem ritualizada, individual, em pequenos grupos ou em redes de pares, fundamental para a construção das identidades. No contexto da pesquisa, o sentido de jogo dos "rachas" se articula ao sentido de rito permanente de virilidade, como proposto por Le Breton ${ }^{31}$, no qual a expressão de valores centrais de um modelo tradicional e hegemônico de masculinidade se fazem presentes por meio da comprovação pública de coragem, competição, audácia e desafio. Esse modelo foi discutido amplamente por autores como Almeida ${ }^{35}$, Calpe $^{36}$, Cecchetto ${ }^{37}$, Connell ${ }^{38}$ e Kimmel ${ }^{39}$ em diferentes contextos socioculturais. O domínio técnico e o de competição são demonstrações públicas ritualizadas com a função não de marcar a passagem de uma fase de um status a outro, mas de dar visibilidade e reconhecimento aos olhos dos pares, das garotas e da polícia.

A potência dos motores se transforma em metáfora da potência dos condutores, possibilitando a esses jovens responderem à impotência social com potência tecnológica. Eles têm acesso ao automóvel, esse bem preferencial de consumo, transformando e personalizando carros e motos à sua própria imagem, à medida de suas possibilidades e inseridos em uma ampla rede de trocas de serviços, peças e favores.

Nos dicionários, "rachar" é se romper por excesso de tensão e "racha" é "fenda ou sulco causado por ruptura"; "estilhaço, lasca causados por impacto violento ou explosão". A palavra é sugestiva, pois no senso comum se refere, de forma pejorativa, ao sexo feminino. Esse sentido não é sem importância, dada a frequente analogia que os "rachadores" fazem com o prazer experimentado na relação de seus corpos com a máquina acelerada e com o gozo sexual: "é melhor do que sexo". As mulheres, entretanto, parecem representar um papel de espectadoras diante das quais os jovens se apresentam e encenam suas performances. As mais bonitas são também signos de prestígio ao lado dos veículos, um tipo de presença-ausência. Em todo caso, são mais difíceis de serem compreendidas do que os motores, conforme afirma um dos participantes: "casei com o meu carro". Além disso, são discriminadas nesse universo: "[...] aos 14 anos pela primeira vez descobri a sensação de ter um volante nas mãos, essa sensação de superioridade masculina, você não admite que uma mulher dirija lentamente na sua frente, não só mulher, mas japonês, velhos, nada que seja lento".

Nos ritos permanentes de virilidade, dois aspectos desempenham um papel primordial: as pulsões de onipotência, sobretudo durante a adolescência/juventude, que dirigem contra a rotina morna de uma cotidianidade que transmite experiências de impotência e lhes dá a impressão de não terem escolhas ou controle sobre os seus percursos de vida; e a necessidade identitária que os leva à busca de reconhecimento em suas redes com quais compartilham gostos e interesses por marcas de carros e motos, música e estilos.

Poderíamos falar de (micro)resistências que tendem a benefícios pessoais e identitários, por meio de performances e competências que permitem reconhecimento necessário à formação de suas identidades, proporcionado ganhos expressivos de singularização social, de autenticidade e de reconhecimento. O que esses jovens parecem expressar, nas palavras de Ferreira27, são um:

[...] desejo de existência, de protagonismo e de emancipação, enquanto práticas potenciadoras de um sentimento de estar activamente no mundo e de ser "alguém" no mundo como compensação de uma espécie de sentimento de inexistência (Aubert, 2005), particular ao estatuto de cidadania dos jovens. (apud Ferreira, p. 120)

O sociólogo português José Machado Pais ${ }^{40}$ ajuda a compreender as práticas dos "rachadores" ao chamar a atenção para a dimensão de resistência grupal, presente em várias manifestações dos grupos urbanos juvenis, nas quais o corpo se destaca como locus de expressão e de enfrentamento: grafiteiros/pichadores com inscrições, desenhos e assinaturas que ocupam a cidade e skatistas que deslizam pelas ruas afrontando as convenções urbanas. 


\section{Considerações finais}

Os dados de campo permitem reforçar um dos argumentos centrais da análise que é a interpretação do risco, ou de uma das formas de arriscar a vida relacionada ao sentido de riscoaventura, como possibilidade de construção identitária. No caso dos "rachadores", foi necessário alargar as teorias sobre risco de maneira a incorporar também o sentido de risco buscado, almejado, enfrentado, uma vez que a busca pelas sensações intensas faz parte do jogo e propicia reconhecimento entre os pares e um sentimento de potência.

Se os jovens "rachadores" não falam de risco e sim de "brincadeira" é porque aprenderam a testar e a controlar a vertigem nas experiências lúdicas e nos jogos de competição relacionados a manobras e velocidade; e, ao mesmo tempo, a valorizar a demonstração de coragem e de audácia, de forma a ritualizar seu desempenho. Além de serem reforçadas no processo de socialização, tais práticas demonstram que não há contradição nas atitudes de superestimação de si e de subavaliação do risco, próprias do contexto sociocultural atual, bem analisado por Peretti-Watel2 ${ }^{20}$, que, de um lado, conjura riscos e multiplica seguros de todo tipo e, de outro, valoriza o sucesso material, a iniciativa, a performance e o reconhecimento pessoais. Esse contexto desenvolve uma tendência securitária com relação aos riscos, mas cria, ao mesmo tempo, novas situações-limite (a invenção do carro acompanha a do acidente) e convive com a necessidade de experiências extremas.

Podemos pensar os "rachadores" como aventureiros primários que "correm" riscos sem seguro de vida, pois os seguros simulariam a aventura, ao invés de lhes garantir uma experiência intensa, em um campo de escolhas e de competências próprias, que possibilita enfrentar as experiências de impotência diante das impossibilidades de escolhas e de controle sobre os seus próprios percursos sociais.

\section{Referências}

1. Marin L, Queiroz MS. A atualidade dos acidentes de trânsito na era da velocidade: uma visão geral. Cad Saude Publica. 2000; 16(1):7-21.

2. Souza ER, Minayo MCS. Impacto da violência na saúde dos brasileiros. Brasília (DF): Ministério da Saúde; 2005.

3. Bastos YGL, Andrade SAM, Soares DA. Características dos acidentes de trânsito e das vítimas atendidas em serviço pré-hospitalar em cidade do Sul do Brasil, 1997/2000. Cad Saude Publica. 2005; 21(3):815-22.

4. Carmo PS. Culturas da rebeldia. A juventude em questão. São Paulo: SENAC; 2001.

5. Featherstone M. Automobilities: an introduction. Theory Cult Soc. 2004; 21(4/5):1-24.

6. Cunha R. A pressa de chegar [Internet]. Com Ciência - SBPC Rev Eletronica J Cient. 2007 [citado 3 Mar 2009]; 93:[5 p.]. Disponível em: http://www.comciencia.br/.

7. Sennett R. Carne e pedra. O corpo e a cidade na civilização ocidental. Rio de Janeiro: Record; 1997.

8. DaMatta R, Vasconcellos JG, Pandolfi R. Tanto igualdade quanto hierarquia? O caso da cultura do trânsito no Espírito Santo [Internet]. In: Anais do 32o Encontro Anual da Anpocs; 2008; Caxambu-MG, Brasil. São Paulo: Anpocs; 2008 [citado 17 Dez 2008]. Disponível em: http://200.152.208.135/anpocs/trab/adm/resumo_trabalho.tpl.php?id trabalho=1511.

9. Peirano M. A favor da etnografia. Rio de Janeiro: Relume-Dumará; 1995. 
10. Woortman K. Sobre a formação de antropólogos. Anuário Antropológico/96. Rio de Janeiro: Tempo Brasileiro; 1997. p. 9-31.

11. Goldman M. Os tambores dos mortos e os tambores dos vivos. Etnografia, antropologia e política em Ilhéus, Bahia. Rev Antropol. 2003; 46(2):445-76.

12. Marcus G. Ethnography in/of the world system: the emergence of multi-sited ethnography. Ann Rev Anthropol. 1995; 24:95-117.

13. Ramos AR. Ethnology brazilian style. Brasília: Universidade de Brasília; 1990. p. 1-38. (Trabalhos em ciências sociais, Série Antropologia, 89).

14. Jeolás LS, Kordes H. Risquer sa vie pour une course. Parcours de vie d'une jeunesse brésilienne accro aux courses illégales de voiture et de moto. Paris: L'Harmattan; 2013.

15. Jeolás LS. Les courses ilégales de voitures: le cyberespace comme terrain ethnographique. Altérités. 2008; 5(1). Disponível em: http://www.altérités.ca.

16. Jeolás LS. Pesquisa de campo em comunidades on-line sobre corridas ilegais de rua: velocidade, risco e masculinidade. Cad Campo. 2009; 18:127-43.

17. Menegon VSM, Spink MJ. Novas tecnologias reprodutivas conceptivas: problematizando a comunicação sobre riscos. In: Ferreira V, Ávila MB, Portella AP, organizadores. Feminismo e novas tecnologias reprodutivas. Recife: SOS Corpo; 2007. p.163-88.

18. Douglas M. Risk and blame: essays in cultural theory. Londres: Routledge; 1994.

19. Douglas M. La aceptabilidad del riesgo según las ciencias sociales. Barcelona: Paidós; 1996.

20. Peretti-Watel P. Les "conduites à risque" des jeunes: défi, myopie, ou déni ? Agora, Débats-Jeunesses. 2002; 27:16-33.

21. Le Breton D. Passions du risque. Paris: Métailié; 1991.

22. Le Breton D. Conduites à risque. Des jeux de mort au jeu de vivre. Paris: PUF; 2004.

23. Ribeiro FB. Os modernos cavaleiros do asfalto: risco e transgressão nas estradas portuguesas. Cad Noroeste. 2003; 21(4-5): 53-68. (Sociedade e Cultura 5).

24. Foucault M. Microfísica do poder. Rio de Janeiro: Graal; 1979.

25. Foucault M. Nascimento da biopolítica. São Paulo: Martins Fontes; 2008.

26. Farhi Neto L. Biopolíticas. As formulações de Foucault. Florianópolis (SC): Cidade Futura; 2010.

27. Ferreira VS. O "jovem radical" contemporâneo: novos sentidos de um qualificativo juvenil. Crit Soc Rev Cultura Polit. 2011; 1(2):107-27.

28. Beck U, Giddens A, Lash S. Modernização reflexiva. Política, tradição e estética na ordem social moderna. São Paulo: Unesp; 1997.

29. St-Germain P, Ménard G. Des jeux et des rites. Montréal: Liber; 2008.

30. Segalen M. Rites et rituels contemporains. Paris: Colin; 2009.

31. Le Breton D. Des rites juvéniles de contrebande. In: Yannic A, coordenateur. Le rituel. Paris: CNRS Editions; 2009. p. 25-44.

32. Elias N, Dunning E. A busca da excitação. Lisboa: Difel; 1992.

33. Balandier G. Le Dédale: pour en finir avec le XXe siècle. Paris: Fayard; 1994.

34. Jeffrey $D$, Le Breton $D$, Levy JJ. Jeunesse à risque: rite \& passage. Québec: Les Presses de l'Université Laval; 2005. 
35. Almeida MV. Senhores de si: uma interpretação antropológica da masculinidade. Lisboa: Fim de Século; 2000.

36. Calpe JME. Hombres, motos y riesgo: androcentrismo y sexismo en el mundo de las motos. DEA Licenciado Antropología Social Cultura [Internet]. 1998/99 [citado 28 Fev 2010]; 93: [8 p.]. Disponível em: http://www.telefonica.net/web2/sword/default.htm.

37. Cecchetto FR. Violência e estilos de masculinidade. Rio de Janeiro: FGV; 2004.

38. Connell RW. La organización social de la masculinidad. In: Valdés T, Olavaria J, editeurs. Masculinidad/es. Poder y crisis. Santiago de Chile: Isis Internacional; 1997. (Ediciones de las mujeres n. 24).

39. Kimmel MS. A produção simultânea de masculinidades hegemônicas e subalternas. Horizontes Antropológicos. 1998; 9:103-17.

40. Machado Pais J. Introdução. In: Machado Pais J, Blass LMS, organizadores. Tribos urbanas: produção artística e identidades. São Paulo: Annablume; 2004.

Jeolás LS. Arriesgar la vida por una carrera: riesgo y carreras ilegales de autos y motos. Interface (Botucatu). 2018; 22(67):1173-82.

El artículo se propone analizar prácticas y producción de significados de jóvenes aficionados a carreras ilegales de autos y motos y a maniobras radicales. La investigación etnográfica trata de comprender las conductas de riesgo entre los "pilotos" y el sentido que ellos propios atribuyen al peligro, a la aventura y a las sensaciones corporales presentes en sus prácticas. Eso obliga a ensanchar los significados de riesgo y comprender determinadas prácticas como contrapunto a las bio-políticas o a las formas de control de la vida. Los "pilotos" son jóvenes de clases populares y responden a la impotencia social que los destituye de un capital económico (y social) por medio de un capital tecnológico que les permite el reconocimiento de sus pares y visibilidad social, aunque sea de contrabando, debido a la ilegalidad de esas prácticas, cuando el riesgo-aventura pasa a ser un factor constitutivo de la construcción de la identidad.

Palabras clave: Juventud. Conductas de riesgo. Autos y motos. Carreras ilegales.

Submetido em 02/10/17. Aprovado em 04/12/17. 